\title{
Synthesis, X-Ray Crystal Structure Study, Hirshfeld Surface Analysis, and Biological Activity of N-(2-amino-phenyl)-2-methyl-benzamide
}

\author{
Latha Rani Nagaraju, ${ }^{1}$ Lakshmi Ranganatha Venkataravanappa, ${ }^{2}$ \\ Sridhar Mandayam Anandalwar, ${ }^{1}$ and Shaukath Ara Khanum ${ }^{3}$ \\ ${ }^{1}$ Department of Studies in Physics, University of Mysore, Manasagangotri, Mysuru 570 006, India \\ ${ }^{2}$ Department of Chemistry, The National Institute of Engineering (Autonomous), Manandavadi Road, Mysuru 570 008, India \\ ${ }^{3}$ Department of Chemistry, Yuvaraja's College, University of Mysore, Mysuru 570 005, India
}

Correspondence should be addressed to Sridhar Mandayam Anandalwar; mas@physics.uni-mysore.ac.in

Received 24 July 2016; Accepted 17 October 2016

Academic Editor: Junsheng Yu

Copyright (C) 2016 Latha Rani Nagaraju et al. This is an open access article distributed under the Creative Commons Attribution License, which permits unrestricted use, distribution, and reproduction in any medium, provided the original work is properly cited.

The title compound crystallizes in monoclinic crystal system, with space group $P 2_{1} / c$. The compound exhibits intermolecular interactions of the types $\mathrm{N}-\mathrm{H} \cdots \mathrm{N}, \mathrm{C}-\mathrm{H} \cdots \mathrm{O}$, and $\mathrm{C}-\mathrm{H} \cdots \pi$; intramolecular interactions of the type $\mathrm{N}-\mathrm{H} \cdots \mathrm{N}$. The intercontacts are also studied using Hirshfeld surface analysis. The compound showed no remarkable antibacterial activity when screened against two gram-negative and two gram-positive bacteria.

\section{Introduction}

The title compound is a benzamide derivative. The compound consists of an amide group bridged to a benzene ring to which a methyl is attached on one side and a phenyl ring to which an amino group is attached on the other side. Benzamides are derived from benzoic acid, which are slightly soluble in water and soluble in many organic compounds.

Amides are pervasive in nature. Compounds containing amide groups show many biological activities, mainly antiproliferative, antiviral, antimalarial, general anesthetics, anti-inflammatory, and antimicrobial activities [1]. Literature reveals that the $\mathrm{N}$-substituted benzamides have many pharmacologically important properties such as antifungal, antiallergic, antihypertensive, anti-inflammatory, antibacterial, analgesic, antirheumatic, antipyretic, and anti-HIV activities [2].

Hence, herein we report the synthesis, characterization, $\mathrm{X}$-ray crystal structure study, in vitro antibacterial activity, and Hirshfeld surface analysis of $\mathrm{N}$-(2-amino-phenyl)-2methyl-benzamide.

\section{Experimental}

2.1. Materials and Methods. Chemicals were purchased from Sigma Aldrich Chemical Corporation. ${ }^{1} \mathrm{H}$ NMR spectra were recorded on a Bruker $400 \mathrm{MHz}$ NMR spectrophotometer in DMSO- $\mathrm{d}_{6}$ solvent and the chemical shifts were recorded in $\delta$ (ppm) downfield from tetramethylsilane. Elemental analysis was done using Perkin Elmer 2400 elemental analyzer and results are within $0.4 \%$ of the calculated value. Infrared spectra were recorded on a Perkin Elmer spectrophotometer in the range of $400-4000 \mathrm{~cm}^{-1}$.

2.2. Synthesis of $\mathrm{N}$-(2-amino-phenyl)-2-methyl-benzamide. The mixture of $o$-phenylenediamine $(0.0037 \mathrm{~mol})$ in dry dichloromethane $(15 \mathrm{~mL}), 2,6$-dimethyl pyridine, and 2-methyl-benzoic acid $(0.0037 \mathrm{~mol})$ was stirred for 30 minutes 
<smiles>Cc1ccccc1C(=O)Nc1ccccc1N</smiles>

Scheme 1: Schematic diagram of the title compound.
TABLE 1: Elemental analysis for the title compound.

\begin{tabular}{lcc}
\hline Element & Experimental (\%) & Calculated (\%) \\
\hline Carbon & 74.31 & 74.33 \\
Hydrogen & 6.24 & 6.25 \\
Nitrogen & 12.38 & 12.41 \\
\hline
\end{tabular}

at $25-30^{\circ} \mathrm{C}$. 2-(1H-Benzotriazole-1-yl)-1,1,3,3-tetramethyluronium tetrafluoroborate $(0.0037 \mathrm{~mol})$ was added to the mixture, whose temperature was maintained below $5^{\circ} \mathrm{C}$. The reaction was monitored by Thin Layer Chromatography using chloroform: methanol $(9: 1)$. The reaction mass was diluted with $20 \mathrm{~mL}$ of dichloromethane. The organic layer was washed with water $(25 \mathrm{~mL})$, dried over anhydrous sodium sulfate, concentrated to syrupy liquid, and recrystallized twice by ethyl ether to afford N-(2-amino-phenyl)-2-methylbenzamide, in good yield of $90 \%$. The melting point of the compound is $94-96^{\circ} \mathrm{C}$. The obtained crystals were white in color (Scheme 1).

2.3. X-Ray Diffraction. A suitable white single crystal was selected to collect X-ray diffraction data. Data were collected on a Bruker Kappa Apex II single crystal X-ray diffractometer equipped with $\mathrm{Cu} K_{\alpha}$ radiation and CCD detector [3]. Crystal structure was solved by direct methods using SHELXS-97. After locating all nonhydrogen atoms, the structure was refined by full-matrix least-squares method using SHELXL97 [4]. The obtained model was refined by isotropic thermal parameters later by anisotropic thermal parameter. Hydrogens were placed at chemically acceptable positions. 156 parameters were refined with 1929 unique reflections which converged the residual $(R)$ to 0.057 .

2.4. In Vitro Antibacterial Activity. As N-substituted benzamides and their derivatives have numerous biological activities, it is worthwhile to investigate the antibacterial activity of the newly synthesized compound.

Antibacterial activity was examined against two grampositive bacteria, namely, Bacillus subtilis (MTCC number 121) and Staphylococcus aureus (MTCC number 7443), and two gram-negative bacteria, namely, Proteus vulgaris (MTCC number 742) and Escherichia coli (MTCC number 730). The bacterial strains were inoculated in nutrient broth and kept for overnight culture at $37^{\circ} \mathrm{C}$. Minimum inhibitory concentration (mic) is the lowest concentration at which blue color of the dye (indicator) turns to pink color [5]. MIC was determined by microbroth dilution method using resazurin (7-hydroxy-3H-phenoxazin-3-one 10-oxide) as an indicator. Resazurin is a blue nonfluorescent, nontoxic, oxidation-reduction indicator. This was performed on 96well microtiter plates [6].

For susceptibility testing the plates were prepared in duplicates. Nutrient broth of $50 \mu \mathrm{L}$ was distributed to all the wells. $50 \mu \mathrm{L}$ compound was added to third and fourth wells. Serial dilution was performed from the fourth well till the concentration reaches $0.39 \times 10^{-2} \mathrm{mg} / \mathrm{mL}$. Finally, $10 \mu \mathrm{L}$ of bacterial suspension was added to all the wells.

The concentrations of the prepared solutions were as follows: $0.5 \mathrm{mg} / \mathrm{mL}, 0.25 \mathrm{mg} / \mathrm{mL}, 0.125 \mathrm{mg} / \mathrm{mL}, 0.625 \times$ $10^{-1} \mathrm{mg} / \mathrm{mL}, 0.3125 \times 10^{-1} \mathrm{mg} / \mathrm{mL}, 0.156 \times 10^{-1} \mathrm{mg} / \mathrm{mL}$, $0.78 \times 10^{-2} \mathrm{mg} / \mathrm{mL}$, and $0.39 \times 10^{-2} \mathrm{mg} / \mathrm{mL}$. Blue color indicates that the compound inhibits the growth of the bacteria, whereas pink color indicates the bacterial growth.

Inoculated plates were incubated at $37^{\circ} \mathrm{C}$ for 24 hours. One hour before the end of incubation $10 \mu \mathrm{L}$ of resazurin was added to all the wells. The plates were incubated for another hour. The change in color was assessed visually. The MIC was recorded.

\section{Results and Discussions}

3.1. Elemental Analysis. In order to confirm the chemical composition of the synthesized compound, carbon (C) and hydrogen $(\mathrm{H})$ analysis was carried out. The experimental and calculated percentages of $\mathrm{C}$ and $\mathrm{H}$ are given in Table 1. The differences between experimental and calculated percentages of $\mathrm{C}$ and $\mathrm{H}$ were very small and are within the experimental errors. This confirms the formation of the product in the stoichiometric proportion.

3.2. FT-IR Spectral Analysis. In FT-IR spectra the peaks observed at $1660 \mathrm{~cm}^{-1}$ are assigned to $\mathrm{C}=\mathrm{O}$ of carbonyl of the amide group. The peak at $1715 \mathrm{~cm}^{-1}$ is for $\mathrm{N}-\mathrm{H}$ stretching vibrations.

3.3. ${ }^{1} H$ NMR Spectral Analysis. The ${ }^{1} \mathrm{H}$ NMR spectra of the compound are shown in Figure 1. The NMR peak at $\delta 2.25$ $(\mathrm{s}, 3 \mathrm{H})$ clearly indicates that the three hydrogens of methyl group are attached to aromatic ring. The peak at $\delta 4.25$ (bs, $2 \mathrm{H})$ corresponds to the two hydrogens of the amino group. The peaks at $\delta 7.15-7.52$ refer to eight aromatic hydrogens of the compound.

3.4. X-Ray Crystal Structure Determination. The compound $\mathrm{C}_{14} \mathrm{H}_{14} \mathrm{~N}_{2} \mathrm{O}$ crystallizes in monoclinic crystal system, with space group $P 2_{1} / c$. The unit cell parameters are $a=$ 11.471(4) $\AA, b=8.269(3) \AA, c=12.518(4) \AA$, and $\beta=$ $96.155(14)^{\circ}$. The details of the crystal data and structure refinement are given in Table 2. The geometrical calculations were carried out using the program PLATON [7]. The molecular and packing diagrams were generated using Mercury [8]. Figure 2 shows the ORTEP diagram of the molecule with thermal ellipsoids drawn at $50 \%$ probability. The bond 

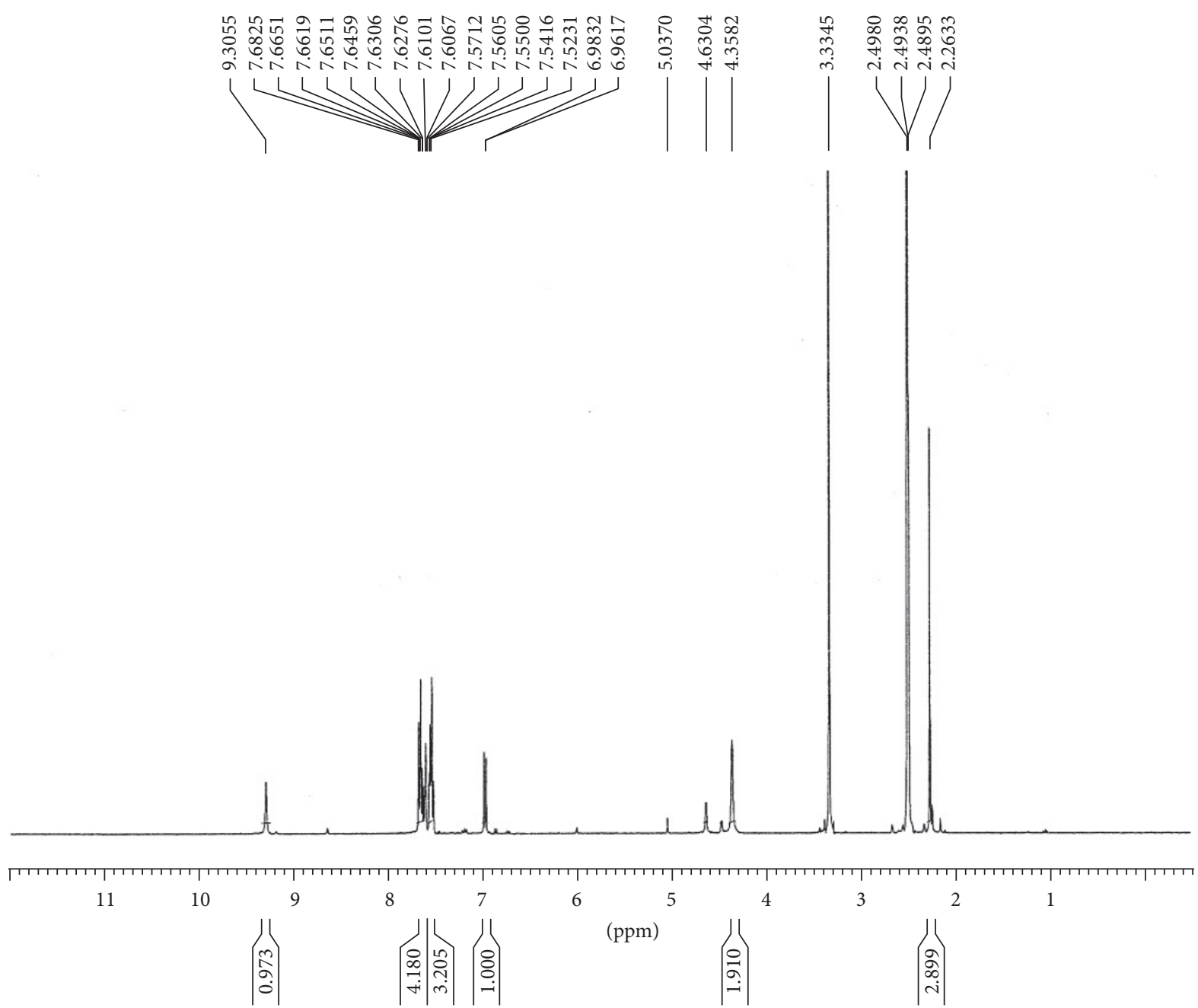

Figure 1: ${ }^{1} \mathrm{H}$ NMR spectra of the title compound.

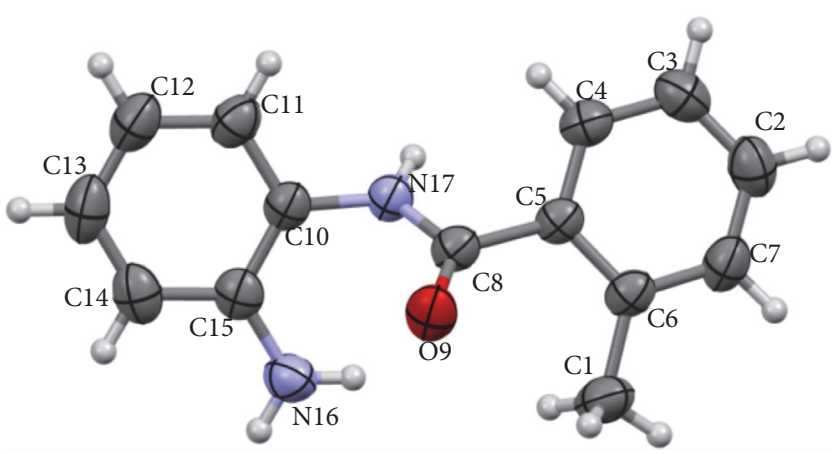

FIGURE 2: ORTEP diagram of the molecule with thermal ellipsoids drawn at 50\% probability.

distances and angles are listed in Table 3. Torsion angles are listed in Table 4.

The phenyl rings are planar. The r.m.s. deviation of the ring $\mathrm{C} 2-\mathrm{C} 7$ (ring- $1 / \mathrm{Cg}(1)$ ) from the mean plane is $0.011(2) \AA$. Atoms C5 and C6 deviate by 0.010(2) $\AA$ from the mean plane defined for the ring. The r.m.s. deviation of the ring $\mathrm{C} 10-\mathrm{C} 15$ (ring- $2 / C g(2))$ from the mean plane is $0.000(2) \AA$. This ring is highly planar. The $\mathrm{O} 9=\mathrm{C} 8$ is $1.240(2)^{\circ}$; this confirms the double bond character.

Ring- 1 and ring- 2 are $s p 2$ hybridized. They are described by the torsion angles $1.13^{\circ}$ and $0.00^{\circ}$, respectively, which suggest that they adopt + syn-periplanar $(+s p)$ conformation. 
TABLE 2: The crystal data and structure refinement details.

\begin{tabular}{|c|c|}
\hline CCDC deposit number & 1418787 \\
\hline Empirical formula & $\mathrm{C}_{14} \mathrm{H}_{14} \mathrm{~N}_{2} \mathrm{O}$ \\
\hline Formula weight & 226.27 \\
\hline Temperature & $293 \mathrm{~K}$ \\
\hline Wavelength & $1.54178 \AA$ \\
\hline Crystal system & Monoclinic \\
\hline Space group & $P 2_{1} / c$ \\
\hline Cell dimensions & $\begin{array}{l}a=11.471(4) \AA \\
b=8.269(3) \AA \\
c=12.518(4) \AA \\
\beta=96.155(14)^{\circ}\end{array}$ \\
\hline Volume & $1180.5(7) \AA^{3}$ \\
\hline$Z$ & 4 \\
\hline Density (calculated) & $1.273 \mathrm{Mg} \mathrm{m}^{-3}$ \\
\hline Absorption coefficient & $0.619 \mathrm{~mm}^{-1}$ \\
\hline$F_{000}$ & 480 \\
\hline Crystal size & $0.210 \times 0.210 \times 0.210 \mathrm{~mm}$ \\
\hline$\theta$ range for data collection & $3.88^{\circ}$ to $64.69^{\circ}$ \\
\hline Index ranges & $\begin{array}{l}-13 \leq h \leq 13 \\
-9 \leq k \leq 9 \\
-12 \leq l \leq 14\end{array}$ \\
\hline Reflections collected & 9047 \\
\hline Independent reflections & $1929\left[R_{\mathrm{int}}=0.0384\right]$ \\
\hline Refinement method & $\begin{array}{l}\text { Full-matrix least-squares } \\
\text { on } F^{2}\end{array}$ \\
\hline Data/restraints/parameters & $1929 / 0 / 156$ \\
\hline Goodness-of-fit on $F^{2}$ & 1.067 \\
\hline Final $[I>2 \sigma(I)]$ & $R 1=0.057, w R 2=0.1627$ \\
\hline Largest diff. peak and hole & 0.267 and $-0.428 \mathrm{e}^{-3}$ \\
\hline
\end{tabular}

TABLE 3: Selected bond lengths and bond angles ( $\AA$, deg.).

\begin{tabular}{lccc}
\hline Atoms & Distances & Atoms & Angles \\
\hline O9-C8 & $1.240(2)$ & C8-N17-C10 & $125.86(14)$ \\
C1-C6 & $1.504(3)$ & N17-C10-C15 & $121.87(15)$ \\
N17-C8 & $1.346(2)$ & C11-C12-C13 & $119.14(19)$ \\
N17-C10 & $1.424(2)$ & N16-C15-C10 & $121.05(16)$ \\
C2-C3 & $1.370(3)$ & N16-C15-C14 & $120.69(17)$ \\
C14-C15 & $1.392(3)$ & C12-C13-C1 & $120.94(18)$ \\
C13-C14 & $1.375(3)$ & C10-C15-C14 & $118.06(16)$ \\
C11-C12 & $1.378(3)$ & O9-C8-N17 & $122.60(15)$ \\
C10-C11 & $1.383(3)$ & N17-C10-C11 & $117.23(16)$ \\
C12-C13 & $1.385(3)$ & C4-C5-C8 & $119.82(15)$ \\
\hline
\end{tabular}

Ring- 1 and $\mathrm{C}=\mathrm{O}$ of the amide group are -anti-clinal $(-a c)$, this is confirmed by the torsion angle $-131.88(19)^{\circ}$ for $\mathrm{C} 4-\mathrm{C} 5-$ C8-O9.

The torsion angle between two phenyl rings bridged via amide group is $-175.47(16)^{\circ}$ (C5-C8-N17-C10); this is greater when compared to the corresponding values
TABLE 4: Selected torsion angles (deg.).

\begin{tabular}{lccc}
\hline Atoms & Angle & Atoms & Angle \\
\hline C5-C8-N17-C10 & $-175.47(16)$ & C2-C3-C4-C5 & $-0.6(3)$ \\
N17-C10-C11-C12 & $175.43(18)$ & C11-C10-N17-C8 & $124.64(19)$ \\
N17-C10-C15-C14 & $-175.19(16)$ & C4-C5-C8-N17 & $47.3(2)$ \\
O9-C8-N17-C10 & $3.7(3)$ & C11-C10-C15-N16 & $174.99(17)$ \\
C7-C2-C3-C4 & $1.5(3)$ & C11-C12-C13-C14 & $0.0(4)$ \\
C3-C4-C5-C6 & $-1.1(3)$ & N17-C10-C15-N16 & $-0.2(3)$ \\
C4-C5-C8-O9 & $-131.88(19)$ & C1-C6-C7-C2 & $176.30(19)$ \\
\hline
\end{tabular}

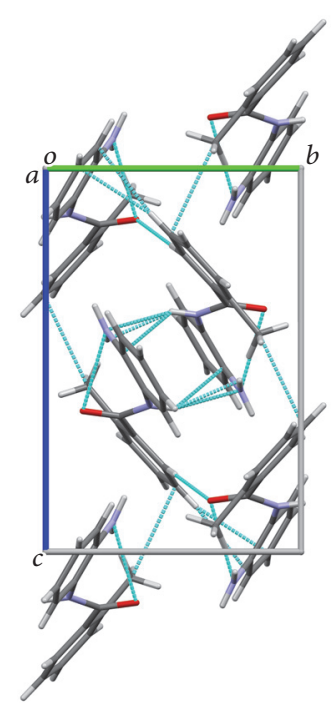

FIGURE 3: Packing of molecules when viewed along $a$-axis.

of $-168.48(17)^{\circ}$ and $-173.38(16)^{\circ}$ for the isomeric benzamides 2-iodo-N-(2-nitrophenyl)benzamide (I) and N-(2iodophenyl)-2-nitrobenzamide (II), respectively [9]. This may be due to the presence of methyl group attached to benzamide or the amino group attached to the phenyl ring or ring-2.

The packing views of the molecules down $a$ - and $b$-axes are shown in Figures 3 and 4, respectively. The molecules are linked by the intermolecular interactions by three hydrogen bonds of types $\mathrm{N}-\mathrm{H} \cdots \mathrm{N}, \mathrm{C}-\mathrm{H} \cdots \mathrm{O}$, and $\mathrm{C}-\mathrm{H} \cdots \pi$. The molecule is also stabilized by weak intermolecular interactions of type $\mathrm{C}-\mathrm{H} \cdots \pi$. Atom $\mathrm{C} 3$ of ring- 1 in a molecule acts as a donor to the C13-C14 (ring-2) atoms of another molecule. In addition, the molecule exhibits intramolecular interactions of types $\mathrm{N}-\mathrm{H} \cdots \mathrm{O}$ and $\mathrm{N}-\mathrm{H} \cdots \mathrm{N}$. The hydrogen bond geometries are shown in Table 5 .

3.5. Hirshfeld Surface Analysis. CrystalExplorer 3.1 [10] program was used for understanding the interactions and the connectivity among the molecules efficiently. The crystallographic information file (.cif) was imported to the CrystalExplorer to generate the Hirshfeld surfaces. The Hirshfeld surface is the region around the molecule in the crystal space which can be considered as the boundary separating two regions-the interior (the reference molecule) and the 


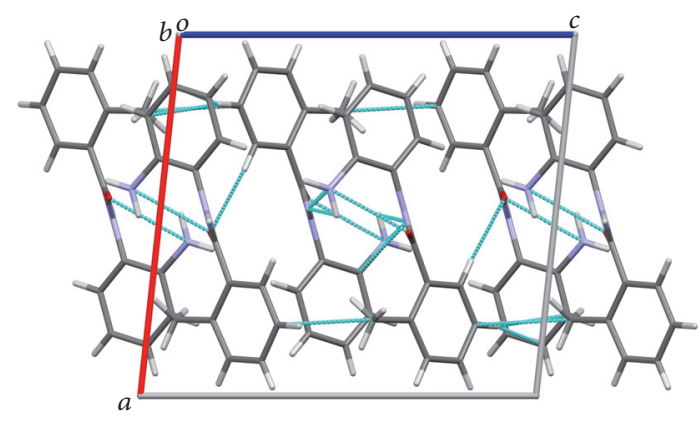

Figure 4: Packing of molecules when viewed along $b$-axis.

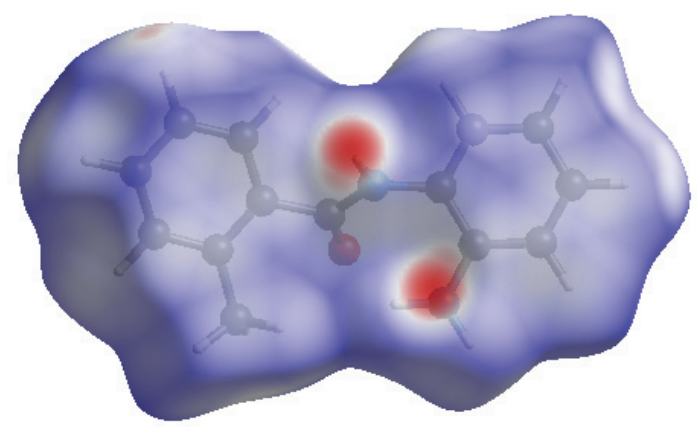

FIGURE 5: $d_{\text {norm }}$ mapped on Hirshfeld surface for the visualization of the intercontacts of the title compound.

exterior (neighboring molecules) [11]. The Hirshfeld surface of the title compound is shown in Figure 5. The red region indicates the hydrogen bond acceptors of $\mathrm{N}-\mathrm{H} \cdots \mathrm{N}$ and $\mathrm{C}-$ $\mathrm{H} \cdots \mathrm{O}$ interactions (N17-H17 $\cdots \mathrm{N} 16$ and $\mathrm{C} 4-\mathrm{H} 4 \cdots \mathrm{O} 9$ ).

The fingerprint plot shows the percentage contributions to the total Hirshfeld surface area. The fingerprint plot data is shown in Table 6. Figures 6(a), 6(b), 6(c), 6(d), 6(e), and 6(f) show the fingerprint plots of the title compound. The major contribution (56.0\%) is from $\mathrm{H} \cdots \mathrm{H}$ contacts. In Figure 6(a) the wings are due to the $\mathrm{C}-\mathrm{H} \cdots \pi$ interactions.

3.6. In Vitro Antimicrobial Activity. The results of biological activity of the title compound are given in Table 7. The resazurin assay showed that the compound has lower-toaverage activity against various tested bacterial strains. The results of the compound with tested bacterial strains were compared with streptomycin. Streptomycin was used as standard in the experiment. The compound showed better/average activity against gram-negative bacteria Proteus vulgaris than any other bacteria, though it never outperforms streptomycin.

\section{Conclusion}

In this research work we have discussed the synthesis of the compound $\mathrm{N}$-(2-amino-phenyl)-2-methyl-benzamide. The preliminary characterizations like elemental analysis, FT-IR,
TABLE 5: Hydrogen bond geometry ( $\AA$, deg.).

\begin{tabular}{lcccc}
\hline $\mathrm{D}-\mathrm{H} \cdots \mathrm{A}$ & $\mathrm{D}-\mathrm{H}$ & $\mathrm{H} \cdots \mathrm{A}$ & $\mathrm{D} \cdots \mathrm{A}$ & $\mathrm{D}-\mathrm{H} \cdots \mathrm{A}$ \\
\hline $\mathrm{N}(17)-\mathrm{H}(17) \cdots \mathrm{N}(16)^{(\mathrm{a})}$ & 0.86 & 2.31 & $3.123(2)$ & 158 \\
$\mathrm{C}(4)-\mathrm{H}(4) \cdots \mathrm{O}(9)^{(\mathrm{b})}$ & 0.93 & 2.53 & $3.462(3)$ & 175 \\
$\mathrm{~N}(16)-\mathrm{H}(16 \mathrm{~B}) \cdots \mathrm{O}(9)^{*}$ & 0.86 & 2.47 & $2.948(2)$ & 116 \\
$\mathrm{~N}(16)-\mathrm{H}(16 \mathrm{~B}) \cdots \mathrm{N}(17)^{*}$ & 0.86 & 2.57 & $2.874(2)$ & 102 \\
\hline
\end{tabular}

${ }^{*}$ Intramolecular hydrogen bond interactions.

Symmetry codes: (a) $1-x, 1-y, 1-z$; (b) $1-x, 1 / 2+y, 3 / 2-z$.

TABLE 6: Percentage of various intermolecular contacts contributing to Hirshfeld surface.

\begin{tabular}{lccc}
\hline Intercontacts & $\begin{array}{c}\text { Contribution } \\
(\%)\end{array}$ & Intercontacts & $\begin{array}{c}\text { Contribution } \\
(\%)\end{array}$ \\
\hline $\mathrm{H} \cdots \mathrm{H}$ & 56.0 & $\mathrm{C}-\mathrm{C}$ & 3.4 \\
$\mathrm{C}-\mathrm{H} / \mathrm{H} \cdots \mathrm{C}$ & 27.7 & $\mathrm{~N}-\mathrm{H} / \mathrm{H} \cdots \mathrm{N}$ & 2.6 \\
$\mathrm{O}-\mathrm{H} / \mathrm{H} \cdots \mathrm{O}$ & 9.8 & $\mathrm{~N}-\mathrm{O} / \mathrm{O}-\mathrm{N}$ & 0.4 \\
\hline
\end{tabular}

TABLE 7: MIC of the title compound against various bacterial strains.

\begin{tabular}{lcc}
\hline \multirow{2}{*}{ Bacterial strains } & \multicolumn{2}{c}{ MIC $(\mathrm{mg} / \mathrm{mL})$} \\
& Streptomycin (std.) & Compound \\
\hline Bacillus subtilis & $0.3125 \cdot 10^{-1}$ & 0.125 \\
Staphylococcus aureus & $0.3125 \cdot 10^{-1}$ & 0.125 \\
Proteus vulgaris & $0.156 \cdot 10^{-1}$ & $0.625 \cdot 10^{-1}$ \\
Escherichia coli & $0.78 \cdot 10^{-2}$ & 0.25 \\
\hline
\end{tabular}

and NMR confirms the chemical compositions of the compound. The structure was confirmed by the single crystal Xray diffraction. The intermolecular interactions were studied by Hirshfeld surface analysis. Screening for biological activity showed that the compound shows better antibacterial activity against gram-negative bacteria Proteus vulgaris.

\section{Competing Interests}

The authors declare that there is no conflict of interests regarding the publication of this paper.

\section{Acknowledgments}

The authors are thankful to IoE, Vijnana Bhavana, University of Mysore, Mysuru, for collecting XRD data, to Dr. Maheshwar P. K. and Mr. Nandu, Department of Microbiology, Yuvaraja's College (Autonomous), University of Mysore, Mysuru, for the assistance in evaluating the biological activity. Latha Rani Nagaraju is thankful to UGC, New Delhi, for RFSMS fellowship. Shaukath Ara Khanum acknowledges the financial support provided by the Vision Group on Science and Technology, Government of Karnataka, under the scheme CISEE (VGST/CISSE/2012-13/2882), Department of Information Technology, Biotechnology and Science \& Technology, Bengaluru. 


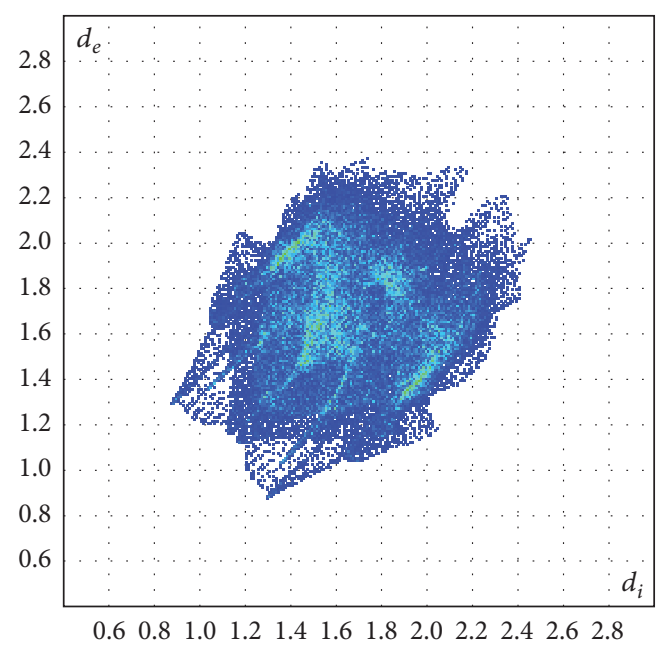

(А)

(a)

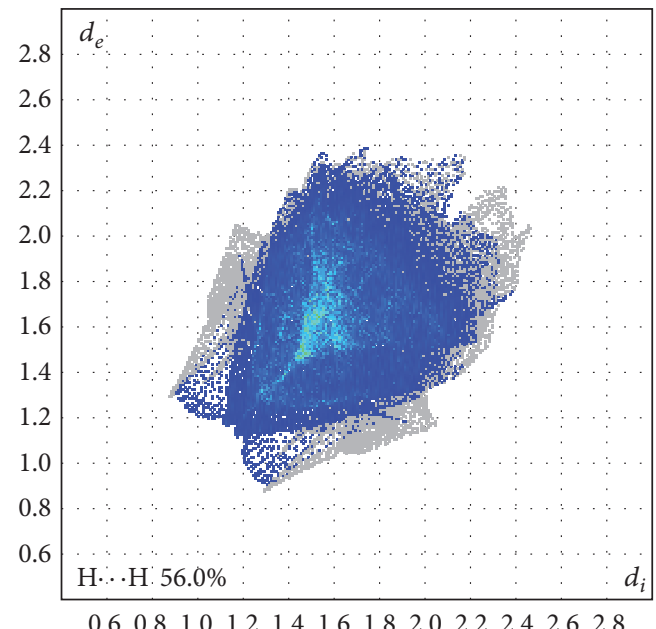

( $)$

(b)

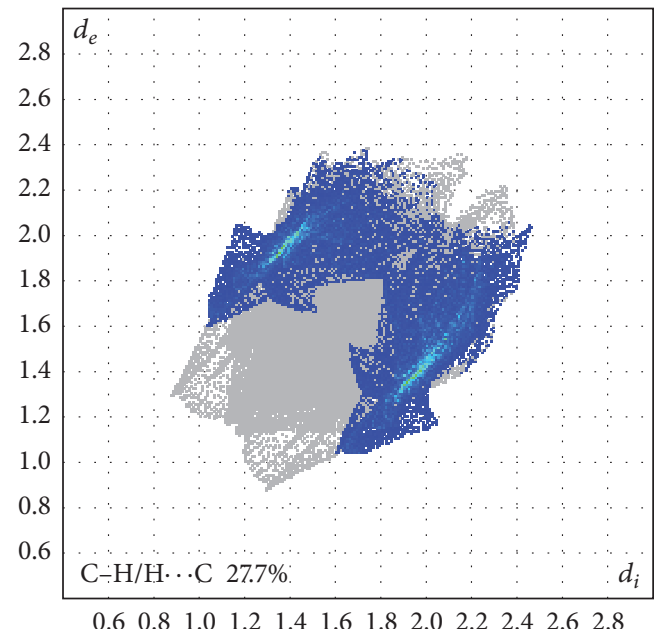

(A)

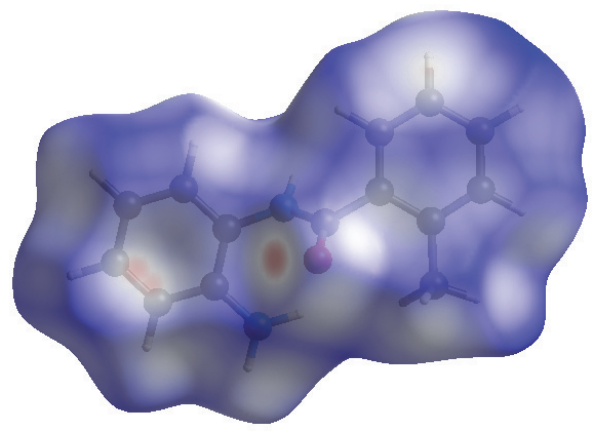

(d)

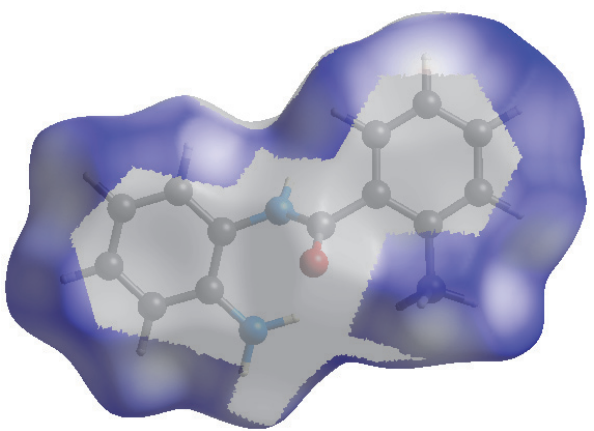

(e)

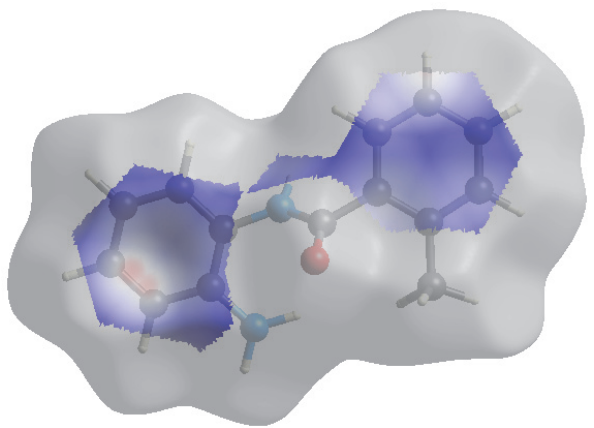

(f)

Figure 6: Fingerprint plot of the title compound. (a) Highlighting full two-dimensional map. (b) Two-dimensional map resolved into $\mathrm{H} \cdots \mathrm{H}$

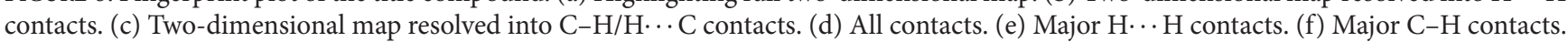




\section{References}

[1] B. S. Priya, S. Naveen, G. Sarala et al., "Crystal structure of 2ethoxy- $N$-[4-(pyrimidin-2-ylsulfamoyl)-phenyl]-benzamide," Analytical Sciences: X-Ray Structure Analysis Online, vol. 22, pp. x235-x236, 2006.

[2] A. Saeeda, N. A. Al-Masoudi, and C. Pannecouque, "In-vitro anti-HIV activity of new thiazol-2-ylidene substituted benzamide analogues," Der Pharma Chemica, vol. 4, no. 1, pp. 106-115, 2012.

[3] Bruker, APEX2, SAINT, \& SADABS, Bruker AXS Inc, Madison, Wis, USA, 2009.

[4] G. M. Sheldrick, SHELX 97. A Program for Crystal Structure Determination, Cambridge University Press, Cambridge, UK, 1997.

[5] S. D. Sarker, L. Nahar, and Y. Kumarasamy, "Microtitre platebased antibacterial assay incorporating resazurin as an indicator of cell growth, and its application in the in vitro antibacterial screening of phytochemicals," Methods, vol. 42, no. 4, pp. 321324, 2007.

[6] A. H. Deborah and J. S. Neil, "Resazurin-based assay for screening bacteria for radiation sensitivity," Methodology, vol. 2, no. 55, pp. 1-6, 2013.

[7] A. L. Spek, "Structure validation in chemical crystallography," Acta Crystallographica, vol. 65, pp. 148-155, 2009.

[8] C. F. Macrae, I. J. Bruno, J. A. Chisholm et al., "Mercury CSD 2.0- new features for the visualization and investigation of crystal structures," Journal of Applied Crystallography, vol. 41, no. 2, pp. 466-470, 2008.

[9] J. L. Wardell, J. M. S. Skakle, J. N. Low, and C. Glidewell, "Contrasting three-dimensional framework structures in the isomeric pair 2-iodo- $N$-(2-nitrophenyl)benzamide and $\mathrm{N}$-(2iodophenyl)-2-nitrobenzamide," Acta Crystallographica Section C Crystal Structure Communications, vol. 61, no. 11, pp. o634o638, 2005.

[10] S. K. Wolff, D. J. Grimwood, J. J. McKinnon, D. Jayatilaka, and M. A. Spackamn, Crystal Explorer 3.1, University of Western Australia, Perth, Australia, 2007.

[11] J. Christian, E. Krzysztof, and H. Loic, “The enrichment ratio of atomic contacts in crystals, an indicator derived from the Hirshfeld surface analysis," International Union of Crystallography (IUCr), vol. 1, part 2, pp. 119-128, 2014. 

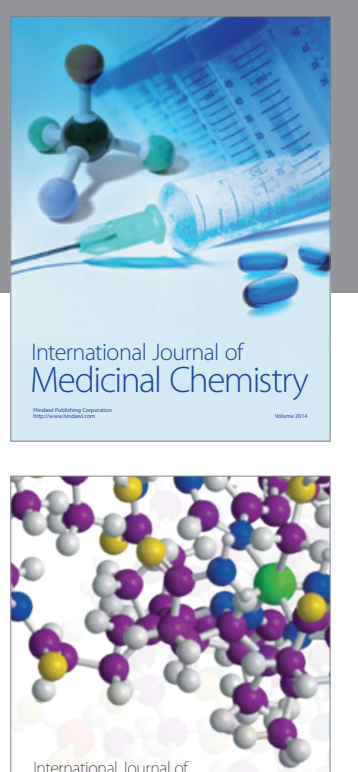

Carbohydrate Chemistry

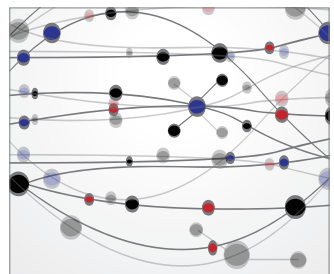

The Scientific World Journal
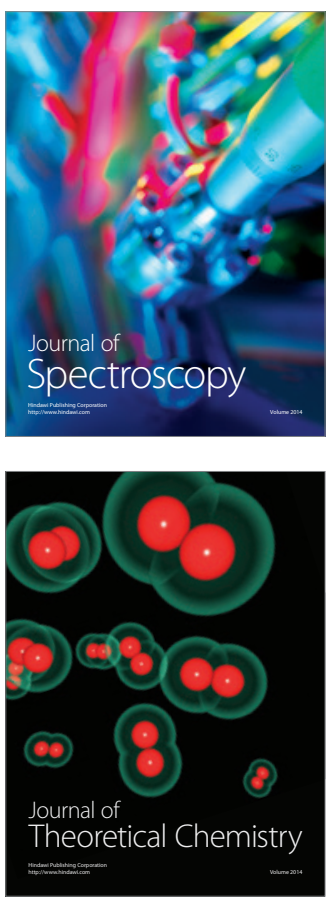
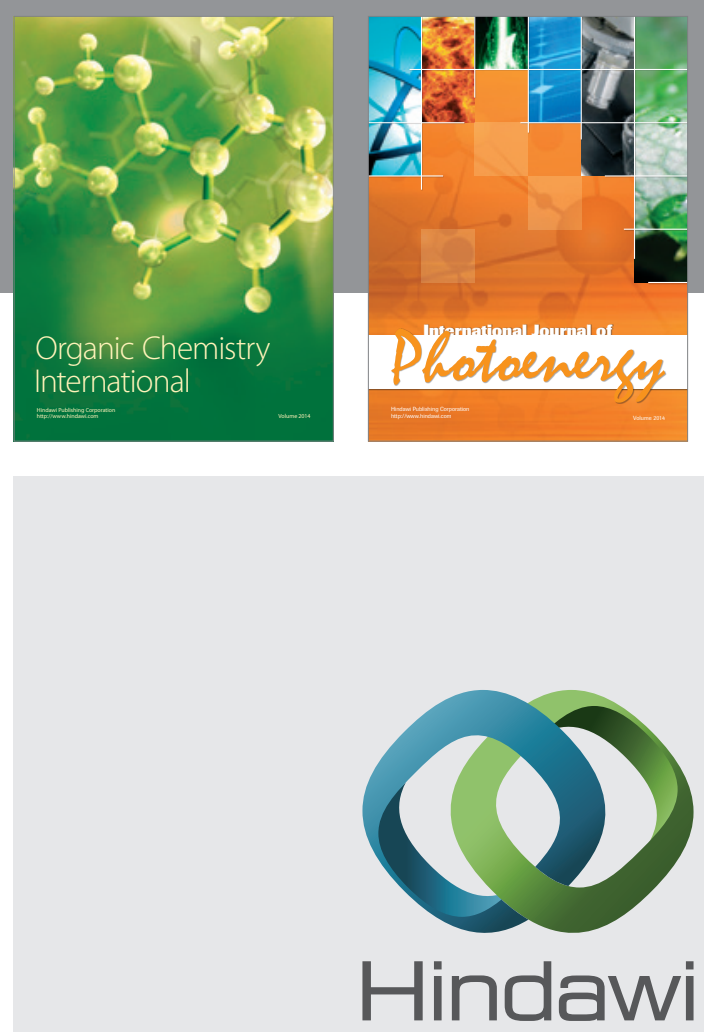

Submit your manuscripts at

http://www.hindawi.com

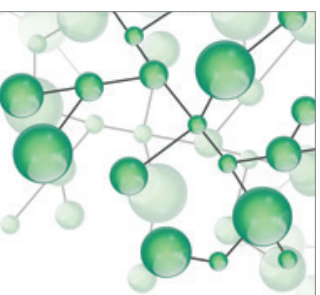

International Journal of

Inorganic Chemistry

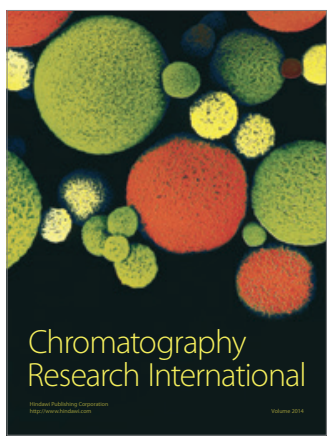

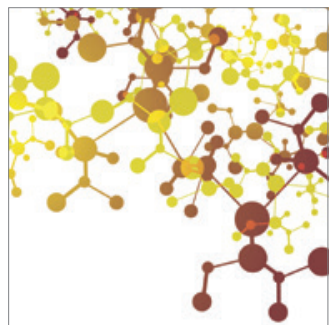

Applied Chemistry
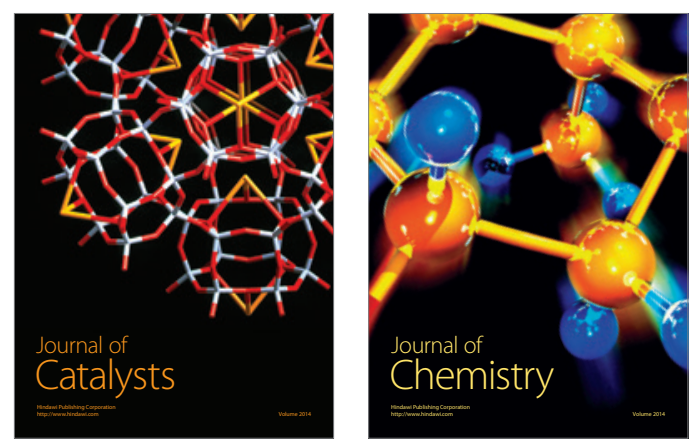
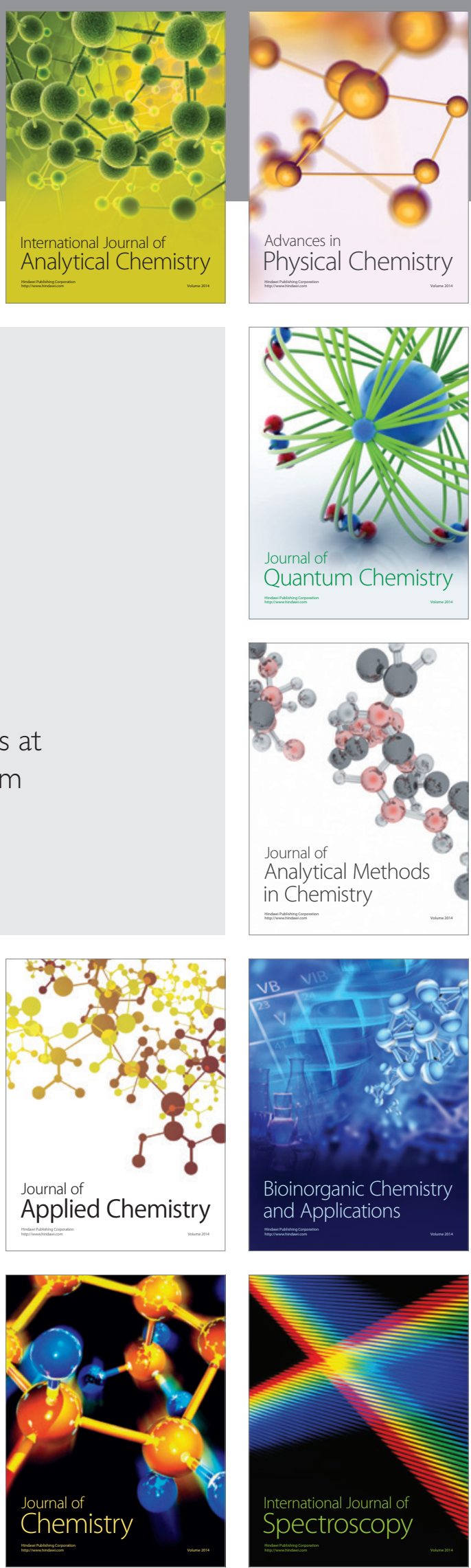